\title{
Digital Educational Computer Games Environments Supporting Education (DECGE-SE)
}

\author{
Thiti Jantakun ${ }^{1} \&$ Thada Jantakoon ${ }^{2}$ \\ ${ }^{1}$ Department of Computer Education, Faculty of Education, Roi Et Rajabhat University (RERU), Roi Et, \\ Thailand \\ ${ }^{2}$ Department of Computer Science, Faculty of Science and Technology, Rajabhat Maha Sarakham University, \\ Maha Sarakham, Thailand \\ Correspondence: Thada Jantakoon, Department of Computer Science, Faculty of Science and Technology, \\ Rajabhat Maha Sarakham University, Maha Sarakham, Thailand. E-mail: thada.phd@ gmail.com
}

Received: February 4, 2021

Accepted: March 7, $2021 \quad$ Online Published: March 15, 2021

doi:10.5539/hes.v11n2p91

URL: https://doi.org/10.5539/hes.v11n2p91

\begin{abstract}
The purposes of the research were 1) to design the Digital Educational Computer Games Environments Supporting Education (DECGE-SE) and 2) to evaluate the DECGE-SE. The research procedure was divided into two phases. The DECGE-SE as follows: (1) Learning: (1.1) Subject area, (1.2) Learning objectives/Player goals, (1.3) Learning Theories, (1.4) Platform and (1.5) Type of game; (2) Instruction: (2.1) Game Cycle and (2.2) Components for educational computer games online; (3) Outcomes and Impacts comprised four elements: (3.1) Knowledge acquisition/content understanding, (3.2) Perceptual and cognitive skills, (3.3) Affective and motivational outcomes and (3.4) Behavioural change. The expert opinions on the DECGE-SE evaluated that it was a very high appropriate level.
\end{abstract}

Keywords: educational game environments, educational digital games, game-based learning, GBL, DECGE-SE

\section{Introduction}

Today's students are no longer the person our educational system was designed to teach. The term is especially popular in the field of education is often used as a reason for making broad assumptions about knowledge. Today's young people's digital book (Becker, 2016) is used to describe the "net generation" who spend most of their time on the Internet by being permanently "open". Coming in the digital age, they have excellent knowledge of computer languages, digital games, and the Internet. "Unlike digital immigrants like older parents and teachers, digital technology, on the other hand, is often described as a tool to increase productivity. Together and motivate learners to re-engage with their education (Papadakis, 2016) and help them develop the new multi-literacy skills necessary for today's knowledge economy (Lacasa, 2013). Between real education and entertainment is a major challenge in making better use of computers' potential and reaching out to populations who are predisposed to learning (An \& Bonk, 2009).

Computer games are well suited to Next Generation Science Standards (NGSS) because they help students learn by doing them and help them develop their knowledge and transferable skills by letting them practice their newly learned skills in different situations. Unlike traditional content-focused standards, NGSS is written according to performance expectations, which outlines what students should be able to do in addition to what they should know to demonstrate their scientific expertise. Each NGSS has three dimensions. Disciplinary core concepts, scientific and engineering practices, and crosscutting concepts through the practice of having sex with NGSS content emphasize the development of scientific knowledge and skills in a real context (NGSS Lead States, 2013). Digital Educational Games is a software application that uses both the nature of video games and computer games to create engaging and inspiring learning experiences to bring specific educational objectives into formal practice. Study successfully such games may be designed to promote learning or development of cognitive skills, or in other ways, in the form of simulations, to allow learners to practice their skills in a virtual environment. Therefore, the researcher had an idea to develop the DECGE-SE as a beneficial guideline for computer games environments for effective digital educational management. 


\section{Literature Review}

\subsection{Novel Approaches to the Design of Educational Digital Games}

In this section we present a number of initiatives that can be broadly categorized into three groups: (1) Multimedia approaches tightly linked to content presentation; (2) those that repurpose pre-existing games for education; (3) a middle category of specially designed games that seeks a balance between fun and educational content.

\subsubsection{Edutainment}

On the other side of the relationship between a focus on education and entertainment, we have found a number of initiatives that are often identified as entertainment. Despite the etymology (Including education and entertainment) this term is often used to label those initiatives that correspond to the intense "educational content" of the spectrum. These initiatives, funded by commercial or public bodies, focus on the formal translation of educational content. (Usually elementary, sometimes in high school) provides a game-like environment. From a game design perspective, those titles are designed based on content and playability will be added to that later. Some authors, such as Kirriemur and McFarlane (Kirriemur \& McFarlane, 2004), MacFarlane and Read (MacFarlane \& Read, 2004) and Sim and MacFarlane (Sim et al., 2006), consider these guidelines a dead end, which makes the term edutainment. Negative burdens when entertainment aspects fail to design, most of the advantages of game-based learning (GBL) in terms of motivation and engagement are lost and the learning experience suffers.

\subsubsection{Repurposing Existing Games for Education}

On the other side of the spectrum, we find a number of initiatives from products designed to be commercial games. Although the development of these games does not take into account the possible educational use. But sometimes their content and models are so detailed that they can have educational value if handled properly, as demonstrated by various initiatives. The main advantage of this approach is cost-effectiveness: Creating brand new educational games in which competitor's commercial games are cost prohibitive in most cases, which makes these recyclable approaches very compelling (Burgos et al., 2007) However, there is a handicap that could affect their educational potential.

\subsubsection{Experiences with Specifically Designed Games}

The conclusions drawn from the previous two subsections are that no end of the spectrum is optimal. The key to success is balancing fun and learning in a gaming design style (Prensky, 2001). Unfortunately, this is not easy because game design is not an accurate science, largely due to the nature of the game. Delicate Fun (Koster, 2004) However, there are many success stories of game design that can be taught, almost ubiquitous, while attracting outside players to the point of playing the game, even if they are not interested in educational content.

\subsection{Game-based Learning and Its Platform}

Technological advancements have allowed GBL to be used in platforms such as desktops, mobile phones and game consoles. In general, each platform has strengths and weaknesses to promote student learning and development. Although computers have enjoyed a high rate of spread in the household market over the past two decades, but using a computer mouse can cause students to have difficulty completing learning activities that require precision clicking and aiming at the target object (Donker \& Reitsma, 2007). Moreover, they may experience physical discomfort. Others (Jacobs \& Baker, 2002) Cellular and tablet platforms are similar in many ways, both of which offer multi-touch interaction, simplifying input commands and Reduces the learning curve and frustration caused by incorrect aiming. Additionally, reviews of these platforms state that the use of multi-touch interactions enhances the learning experience of students and facilitates peer-to-peer collaboration as well as engagement with the study environment. To know (Nacher et al., 2016), the only limitations for these platforms are they are not suitable for group learning, exercise and early motor skills development.

\subsection{Pedagogical Elements in Educational Games}

Generally speaking, game-based learning (GBL) prefers sexual theories, interaction design elements, inspirational aspects, and teaching and creativity factors. Educational games developed mainly based on learning theory. The four main learning theories in GBL are behaviourism, cognitivism, humanism, and constructivism, including the 16 principles of learning (Smith, 2003). Know human beings through experience and learning in a proactive process. Developed behavioural theory involves learning through changes in behaviour or behaviours, shape the environment and principles of reinforcement. Humanist theory deals with factors such as self-determination, value, and user potential (Combs, 1981). Figure 1 provides a summary of the foundations of 
learning theories and their principles.

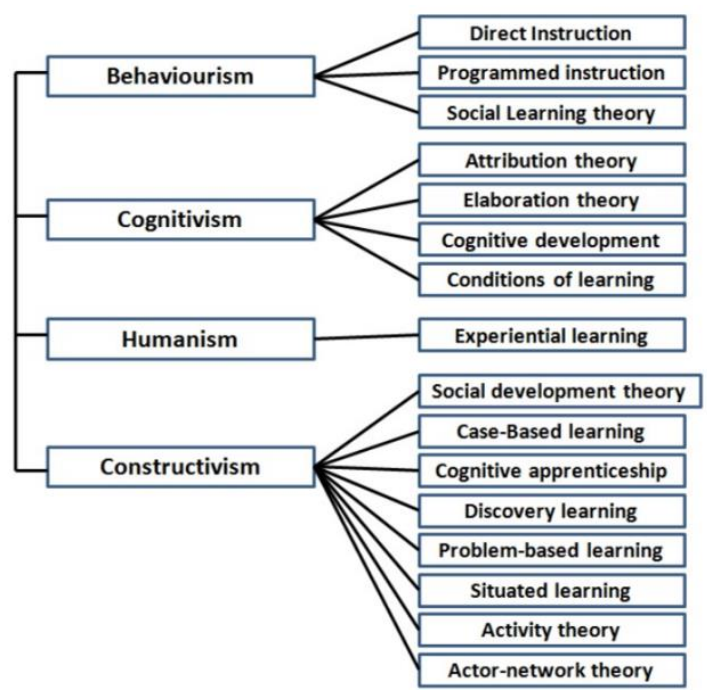

Figure 1. The summary of foundation of learning theories and their principles (Smith, 2003)

\subsection{Game-based Learning Assessment}

Educator-researchers refer to two different kinds of assessment: summative and formative. Summative assessment is typically conducted towards the end of a course of instruction because it is designed to test a person's understanding, retention, or mastery of the subject after a course completion. The After Action Reports (AAR) used by the military are a prime example of summative assessment. Formative assessment of learning, on the other hand, is designed to measure the amount of learning that is still taking place while the course of instruction is on-going, and that assessment can occur as many times as deemed necessary by the trainer or instructor. When taken as a conterminous process, assessment of learning is actually more useful to educators than summative assessment because it helps them fine tune the instructional and learning processes. Feedback, often cited in formative assessment research, has been found to be the single most powerful influence in learning improvement (Wilson et al., 2008). Likewise, in peer- and self-assessment among students of online collaborative learning environments, the feedback received at multiple points over the learning process has been shown to provide students with self-reflection on the learning process, help them identify areas for improvement, and take ownership of their own learning (Lee, 2008). It is clear that an effective formative assessment component would benefit not only the instructors, but also the learners, in an interactive online learning environment such as game-based learning (Figure 2).

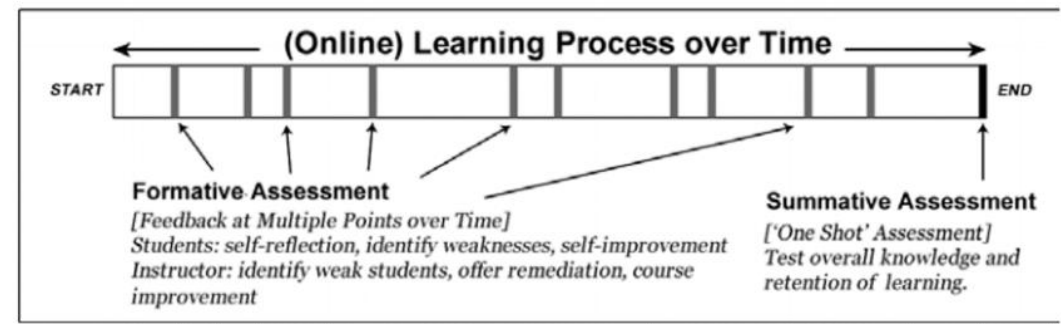

Figure 2. Overview of formative and summative assessments in a learning environment (Wilson et al., 2008)

\section{Methodology}

\subsection{Phase 1: Design the DECGE-SE}

Studies in this phase include theoretical studies and research in new approaches to digital game design for education, game-based learning and platforms, teaching elements in games, education, and assessment of game-based learning. To use as a guideline for determining DECGE-SE Learning Process and Components DECGE-SE will be designed after a document review, and then a survey to receive opinions on the learning 
environment from ten experts.

\subsection{Phase 2: Evaluation of the DECGE-SE}

After gathering all of information and modifying the learning environment, ten educational technology experts were selected to evaluate the DECGE-SE by using five scales in learning environment evaluation form. The expert's selection criteria consisted of (1) the experts must have more than 5 years of experiences in the educational technology field, (2) the experts must have a related work in educational technology, and (3) the experts must have research or teaching experiences with in learning environment.

\section{Result}

Phase 1: Design the DECGE-SE is composed of three key components (Figure3):

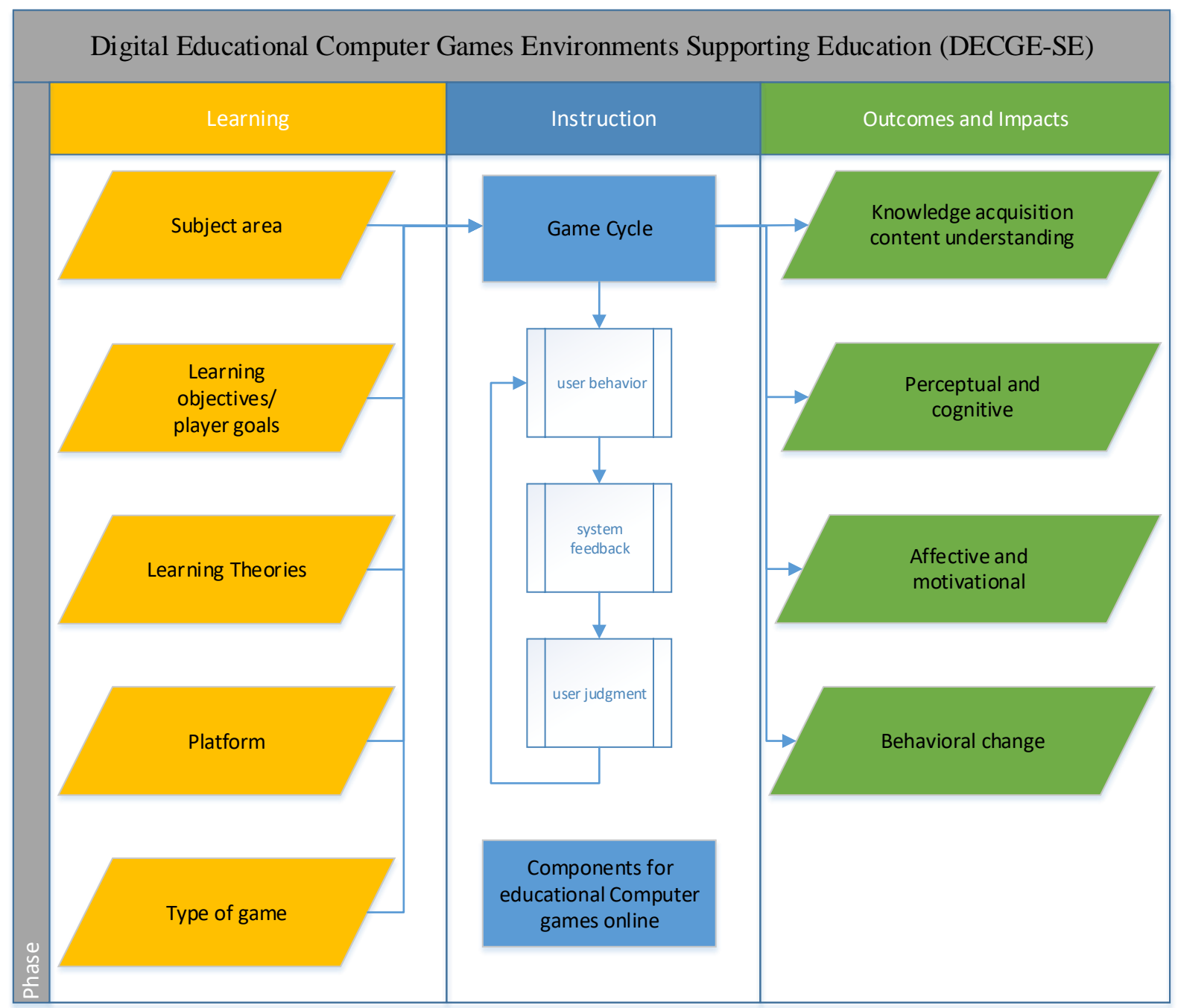

Figure 3. Digital Educational Computer Games Environments Supporting Education (DECGE-SE)

\subsection{Learning}

\subsubsection{Subject Areas}

As there are so many different disciplines, tutors need to analyze the subject content in order to be able to develop a learning environment for games that follow each course. There are a variety of subjects such as math, science, language and society which are the least popular in terms of GBL used in music self-improvement. General knowledge GBL is not used very often, especially in disciplines where the topic is not popular and there may be future research applications for different GBLs. 


\subsubsection{Learning Objectives/ Player Goals}

In an academy perspective, learning has a purpose and an academic subject, comprising a specific content or skill to be learned. This framework aims to develop students' learning in areas such as thinking, communication, music, pronunciation skills, and the ability to learn new words in a language, play an important role in language development and communication. The player's goal is then determined to learn the vocabulary.

\subsubsection{Learning Theories}

Game-based learning generally likes complementary learning theories of interface design, the inspirational aspects, teaching factors, and creativity. Educational games developed mainly based on learning theory. The four main learning theories in GBL are behaviourism, cognitivism, humanism, and constructivism. Learning theories including 16 learning principles.

\subsubsection{Platform}

Platform (games for learning) can be subdivided into PC, Online, Video console, Virtual world (Jantakoon et al., 2019), Mobile and all. Games that support learning through the most popular platforms for delivering games are personal computers (PC), video consoles, and online games. The most popular platform for games optimized for learning is PC. Followed by online, video consoles and mobile, the least popular platforms are virtual worlds and touch tablet technology (Srilaphat \& Jantakoon, 2019).

\subsubsection{Type of Games}

Type of games can be classified into action, strategy, adventure, role-playing, puzzle, simulation, virtual world, generics and not specified.

\subsection{Instruction}

\subsubsection{Game Cycle/Motivation in Instructional Games}

Teaching programs can be designed that incorporate certain features or aspects of the game. These features or characteristics form the game's cycle, which includes three distinct phases. The feedback process of the system provides players with knowledge of the results, which is critical for support, efficiency and motivation. The response of a system to performance can be both positive and negative. In the user judgment process, the comments received are compared with the standards or goals which control user behaviour. This is a judgmental behaviour feedback cycle. If matching the instructional content to the game nature and features is successful, this cycle will result in the gameplay taking place. Repetitive and self-motivated this engagement may lead to the achievement of training objectives and learning outcomes. In addition, constant player involvement can lead to constant involvement, which the cornerstone of computer is gaming.

\subsubsection{Component for Games}

The games components offered include Challenge, Fantasy, Curiosity, Usability, Interface, Mechanics, Game Play / Playability, Story, Entertainment, Mobility and Social. While fantasy and curiosity refer to the game environment that appeal to more players, the usability elements are related to game controls and interfaces. Interfaces are elements that allow players to interact with the game world, while mechanics are the rules that dictate what a player can do for the gameplay and to ensure that the game is played. Playability is often assessed on playability, so Playability is used here, while Story is a sequence of events taking place in the game world. Entertainment involves game elements that promote emotional connection and immersion with the player. For Mobility, this element deals with things that may affect the agility of the game. Finally, the social element deals with the nature of the social game.

\subsection{Outcomes and Impacts}

Outcomes and Impacts of the DECGE-SE involve four major components:

\subsubsection{Knowledge Acquisition/Content Understanding}

Students benefit more from educational computer games in a pedagogical context consisting of both peer collaboration and facilitation intervention (Chatterjee et al., 2011). Similar knowledge is improved using AR games when using custom and guided games (Furio et al., 2013).

\subsubsection{Perceptual and Cognitive Skills}

The traits that promote reasoning and problem-solving are adjustable difficulty, the availability of advice and the ability to maintain and direct cognitive activity. Too much cognition is an obstacle to teaching (Bottino et al., 2009). GBL can benefit internally controlled and highly logical thinking players when these variables are not 
part of teach (Cha et al., 2008).

\subsubsection{Affective and Motivational Outcomes}

3D games for entertainment purposes specifically looking at flow experience (Inal\&Cagiltay, 2007) were the others used games for learning. Flow experience in game play happened more in males. Challenge and complexity of games had more effect on flow experiences than clear feedback.

\subsubsection{Behavioural Change}

All studies in this category are positive and study single player games. Two studies used a 3D game (Vannini et al., 2010) and two 2D games (Sun et al., 2011). Results show that children tend to choose based on what is advertised in the game (Dias \& Agante, 2011).

Phase 2: Evaluation of the DECGE-SE. The results of appropriateness evaluate of the DECGE-SE is rated as very high appropriate level in overall $(\overline{\mathrm{x}}=4.51, \mathrm{~S} . \mathrm{D} .=0.50)$. The results can be seen in Table 1.

Table 1. DECGE-SE Evaluate

\begin{tabular}{llll}
\hline List of Evaluation & $\overline{\mathrm{x}}$ & S.D & Level of appropriateness \\
\hline Learning & & & \\
$\quad$ - Subject areas & 4.50 & 0.52 & very high \\
$\quad$ - Learning objectives & 4.60 & 0.51 & very high \\
- Learning Theories & 4.70 & 0.48 & very high \\
- Platform & 4.50 & 0.50 & very high \\
- Type of game & 4.70 & 0.48 & very high \\
Instruction & & & \\
$\quad$ - Games Cycle & 4.60 & 0.51 & very high \\
$\quad$ - Component for educational games & 4.50 & 0.52 & very high \\
Outcomes and Impacts & & & \\
$\quad$ - Knowledge acquisition/content understanding & 4.30 & 0.48 & high \\
$\quad$ - Perceptual and cognitive skills & 4.30 & 0.48 & high \\
- Affective and motivational outcomes & 4.40 & 0.51 & high \\
- Behavioral change & 4.50 & 0.52 & very high \\
Total & $\mathbf{4 . 5 1}$ & $\mathbf{0 . 5 0}$ & very high \\
\hline
\end{tabular}

\section{Conclusion}

In conclusion, DECGE-SE can be useful learning environments and teaching tools for supporting Education. However it is important to bear in mind, play is one of the very first and most effective ways that learners can get about whatever knowledge they required. Computer games can be an engaging learning environment for the teaching and learning process. Meanwhile computer game can guide the learner step by step to achieve the objective of the learning process base on the learner skill and their preferences. DECGE-SE consists of: Three parts: (1) Learning, (2) Instruction, and (3) Outcomes and Impacts. The experts also evaluated which phase of the DECGE-SE was very high appropriate level for Supporting Education. The results of the DECGE-SE assessment relate to research written by Ahmad et al., (2014) indicating that learning using a computer game learning environment can benefit from an important correlation in computer gaming. Determining how one element works with the other to ensure the game's effectiveness.

\section{References}

Ahmad, M., Rahim, L. A., \& Arshad, N. I. (2014). A review of educational games design frameworks: An analysis from software engineering. In 2014 International Conference on Computer and Information Sciences (ICCOINS). pp. 1-6. https://doi.org/10.1109/ICCOINS.2014.6868452

An, Y., \& Bonk, C. J. (2009). Finding that SPECIAL PLACE: Designing digital game-based learning environments. TechTrends, 53(3), 43-48.

Annetta, L., Mangrum, J., Holmes, S., Collazo, K., \& Cheng, M. T. (2009). Bridging realty to virtual reality: Investigating gender effect and student engagement on learning through video game play in an elementary school classroom. International Journal of Science Education, 31, 1091-1113. https://doi.org/10.1080/09500690801968656

Becker, K. (2016). Choosing and using digital games in the classroom: a practical guide. In Advances in 
Game-Based Learning, Vol. 1, Springer, Dordrecht. https://doi.org/10.1007/978-3-319-12223-6_9

Bottino, R. M., Ott, M., \& Benigno, V. (2009). Digital mind games: Experience-based reflections on design and interface features supporting the development of reasoning skills. In Proceedings of the 3rd European conference on games-based learning (ECGBL), Graz, Austria.

Burgos, D., \& Moreno-Ger, P. (2007). Authoring game-based adaptive units of learning with IMS learning design and he Adventure. International Journal of Learning Technologies, 3(3), 252-268. https://doi.org/10.1504/IJLT.2007.015444

Cha, J., Baek, Y., \& Xu, Y. (2008). Exploring Learner's variables affecting gaming achievement in digital game-based learning. https://doi.org/10.1109/DIGITEL.2008.15

Chatterjee, S., Mohanty, A., \& Bhattacharya, B. (2011). Computer Game-based Learning and Pedagogical Contexts: Initial Findings from a Field Study. Proceedings of the IEEE International Conference on Technology for Education T4E 2011, Chennai, India. pp. 109-115. https://doi.org/10.1109/T4E.2011.25

Combs, A. (1981). Humanistic Education: Too Tender for a Tough World?. The Phi Delta Kappan, 62(6), 446-449. Retrieved from http://www.jstor.org/stable/20385941.

Dias, M., \& Agante, L. (2011). Can advergames boost Children's healthier eating habits? A comparison between healthy and non-healthy food. Journal of Consumer Behaviour, 10(3), 152-160.

https://doi.org/10.1002/cb.359

Donker, A., \& Reitsma, P. (2007). Aiming and clicking in young children's use of the computer mouse. Computers in Human Behaviour, 23(6), 2863-2874. https://doi.org/10.1016/j.chb.2006.06.002

Furio, D., Gonz alez-Gancedo, S., Juan, M. C., Segui, I., \& Rando, N. (2013). Evaluation of learning outcomes using an educational iPhone game vs. traditional game. Computers and Education, 64, 1-23. https://doi.org/10.1016/j.compedu.2012.12.001

Jacobs, K., \& Baker, N. A. (2002). The association between children's computer use and musculoskeletal discomfort. Work, 18(3), 221-226.

Jantakoon, T., Wannapiroon, P., \& Nilsook, P. (2019). Virtual Immersive Learning Environments (VILEs) Based on Digital Storytelling to Enhance Deeper Learning for Undergraduate Students. Higher Education Studies, 9(1), 144-150. https://doi.org/10.5539/hes.v9n1p144

Kirriemur, J., \& McFarlane, A. (2004). Literature review in games and learning. NESTA Futurelab series. Bristol: NESTA Futurelab.

Koster, R. (2004). Theory of fun for game design. Paraglyph.

Lacasa, P. (2013) Learning in Real and Virtual Worlds. Commercial Video Games as Educational Tools, Palgrave Macmillan, New York. https://doi.org/10.1057/9781137312051_7

Lee, H. (2008). Students' perceptions of peer and self-assessment in a higher education online collaborative learning environment. Unpublished Ph.D. dissertation. Retrieved from http://www.lib.utexas.edu/etd/d/2008/leeh55399/leeh55399.pdf

MacFarlane, S., \& Read, J. (2004). Evaluating interactive products for and with children. Computers on human factors in computer systems (CHI 2004). Vienna, Austria.

Nacher, V., Garcia-Sanjuan, F., \& Jaen, J. (2016). Interactive technologies for preschool game-based instruction: Experiences and future challenges. Entertainment Computing, 17, 19-29. https://doi.org/10.1016/j.entcom.2016.07.001

NGSS Lead States. (2013). Next generation science standards: For states, by states. Retrieved from http://www.nextgenscience.org/

Papadakis, S. (2016). Creativity and innovation in European education. 10 years eTwinning. Past, present and the future. International Journal of Technology Enhanced Learning, 8(3/4), 279-296. https://doi.org/10.1504/IJTEL.2016.082315

Prensky, M. (2001). Digital game based learning. New York: McGraw-Hill

Sim, G., \& MacFarlane, S. (2006). All work and no play: Measuring fun, usability, and learning in software for children. Computers and Education, 46(3), 235-248. https://doi.org/10.1016/j.compedu.2005.11.021

Srilaphat, E., \& Jantakoon, T. (2019). Ubiquitous Flipped Classroom Instructional Model with Learning Process 
of Scientific to Enhance Problem-Solving skills for Higher Education (UFC-PS Model). Higher Education Studies, 9(1), 76-85. https://doi.org/10.5539/hes.v9n1p76

Smith, M. K. (2003) Learning Theory. The Encyclopedia of Informal Education. Retrieved from http://infed.org/mobi/learning-theory-models-product-and-process/

Sun, C.-T., Wang, D.-Y., \& Chan, H.-L. (2011). How digital scaffolds in games direct problem-solving behaviors. Computers and Education, 57(3), 2118-2125. https://doi.org/10.1016/j.compedu.2011.05.022

Vannini, N., Enz, S., Sapouna, M., Wolke, D., Watson, S., ... Woods, S. (2010). FearNot!: A computer-based anti-bullying-programme designed to foster peer intervention. European Journal of Psychology of Education, 26(1), 21-44. https://doi.org/10.1007/s10212-010-0035-4

Wilson, K. A., Bedwell, W. L., Lazzara, E. H., Salas, E., Burke, C. S., ... Estock, J. L. (2008). Relationships between game attributes and learning outcomes: Review and research proposals. Simulation \& Gaming, 4O(2), 217-266. https://doi.org/10.1177/1046878108321866

\section{Copyrights}

Copyright for this article is retained by the author(s), with first publication rights granted to the journal.

This is an open-access article distributed under the terms and conditions of the Creative Commons Attribution license (http://creativecommons.org/licenses/by/4.0/). 